\title{
Understanding Benefit and Risk Framework of Fintech Adoption: Comparison of Early Adopters and Late Adopters
}

\author{
Hyun-Sun Ryu \\ Software College, Sungkyunkwan University \\ ryuhs@skku.edu
}

\begin{abstract}
Financial technology (Fintech) service has recently become the focus of considerable attention. Although many researchers and practitioners believe that Fintech can reshape the future of the financial services industry, others are skeptical about the adoption of Fintech because of the considerable risks involved. Therefore, we need to better understand why users are willing or hesitant to adopt Fintech, wherein, positive and negative factors affect their adoption decision. Based on the net valence framework theoretically embedded in theory of reasoned action, we propose a benefit-risk framework which integrates positive and negative factors associated with its adoption. Based on the empirical data collected from 244 Fintech users, this study initially investigates whether perceived benefit and risk significantly impact Fintech adoption intention. We then examine whether the effect of perceived benefit and risk on Fintech adoption intention differs depending on the user types. Results show that legal risk has the biggest negative effect, whereas convenience has the strongest positive effect on Fintech adoption intention. The differences between early adopters and late adopters are driven by different factors.
\end{abstract}

\section{Introduction}

Recent advances in information technology (IT) have led to the rapid development and expansion of new and innovative financial services often called Financial Technology (Fintech). Fintech is a portmanteau that combines the words "financial" and "technology." Fintech is currently an innovative and emerging field that attracts public attention and growing investment. According to Accenture report [33], worldwide investments into Fintech companies and start-ups have risen dramatically only within one year, from 4.05 billion dollars in 2013 to 12.2 billion dollars in 2014. Fintech brings new opportunities to empower people by increasing transparency, reducing costs or cutting middlemen, and making information accessible [38]. Fintech companies are currently expanding their business scope beyond online into mobile such as mobile payment and remittance and from traditional online-banking by financial companies to innovative and differentiated financial services by nonfinancial providers.

Although numerous researchers and practitioners believe that Fintech can reshape the future of the financial industry, the adoption of Fintech adoption is still in doubt. Some users remain skeptical about adopting Fintech because of the considerable risks it involves. The main adoption barriers are risk issues such as financial (e.g., loss of financial outcome and extra fee), regulation (e.g., legal uncertainty for adoption), security and privacy (e.g., vulnerability of security technologies), and operational (e.g., inadequate processes or systems of Fintech companies) concerns. Customers would like to determine the expected value of Fintech adoption considering its benefits as well as risks at the same time, and accordingly make an adoption decision when its benefits are greater than its risks. Thus, Fintech companies are challenged particularly to increase the potential benefits and decrease the potential risks when they offer Fintech to customers [5]. Therefore, we should better understand whether and why customers are willing or hesitating to adopt an emergent financial service, which provides a critical insight for practitioners.

Furthermore, customers have different perceptions regarding benefit and risk depending on user-centric factors because the benefit and risk in each group are different. These differences enable Fintech companies to deeply understand the characteristics of each user group and to effectively deliver their service while meeting the expectations and demands of customers, thereby enhancing the adoption of Fintech. Thus, we categorized Fintech users into early and late adopters and investigated user-group level behavior.

Although a large amount of previous research have identified the main drivers that influence user 
adoption behavior [20, 25, 27, 34], only a few research have simultaneously covered benefits and risks. Moreover, little research has distinguished the different effects of benefit and risk on behavioral intention between Fintech early adopters and late adopters. Therefore, this study determines that both positive (perceived benefit) and negative factors (perceived risk) jointly influence a new emerging financial service adoption process. The study then compares the effects of benefit and risk on Fintech adoption between early adopters and late adopters. This study thus employed on a net valence framework theoretically grounded the theory of reasoned action (TRA) to integrate the benefit and risk of Fintech adoption intention. This study aims to answer the following questions:

1) Do perceived benefit and risk significantly influence Fintech adoption intention?

2) What specific benefit and risk factors influence Fintech adoption intention through customers' perception?

3) Do perceived benefit and risk differ between early and late adopters?

By collecting empirical data from 244 Fintech users in Korea, we explore the effect of perceived benefit and risk on Fintech adoption intention. We then investigate whether the benefit and risk factors differ between early adopters and late adopters. This study can help practitioners understand the benefit and risk perceptions of customers which can be used to devise benefit-increasing and risk-reducing strategies to encourage Fintech adoption. Furthermore, this study provides help to Fintech companies on which factors should be prioritized or avoided when offering services to customers.

\section{Theoretical background}

\subsection{Fintech}

Fintech is an emerging financial service (or sector) combined with financial and IT services (or industries). Fintech is defined differently in the literature. Researchers, such as Sweeney (2015) and Kuo Chuen and Teo (2015), defined Fintech as products or services in financial service companies that were created on highly innovative and disruptive service technologies. Freedman [13] described Fintech relative to building systems that model, value, and process financial products such as bonds, stocks, contracts, and money. Ernst and Young (2015) defined Fintech as an innovation in financial services where technology is the key enabler. Lee (2015) referred to Fintech as a type of business using hardware and software technologies to provide financial services. Arner et al. [1] also defined Fintech in reference to technology-enabled financial solutions.

Although the link between financial and IT services is not a new story, the opportunities, risks and legal implications of Fintech are different from existing electronic finances. The current concerns of policy makers and industry arise not from technology itself but from who is applying the technology of finance[1]. Moreover, the expanding and strengthening role of IT is a special characteristic of Fintech. The role of IT in Fintech is not a faciliator or an enabler for effectively delivering financial services but a true innovator or a disrupter for disrupting the existing value chain by bypassing the exsiting channel. For the reasons, this study defined Fintech as "innovative and disruptive financial services where IT is the key factor in nonfinancial companies." Examples of Fintech are mobile payment and remittance, which represent Fintech the most worldwide. Fintech also includes personal finance management, peer-to-peer (P2P) lending, crowdfunding, and equity investment to customers [3].

\subsection{Benefit-Risk Framework to Explain Adoption}

Consumers often act based on incomplete and imperfect information [21]. As a result, customers often face some degree of risk or uncertainty in adopting decisions. However, risk is not the only factor which consumers depend on in the context of adoption as perceived benefit also provides consumers with an incentive for adoption behavior [37]. Combining perceived benefit and risk, Peter and Tarpey [30] provided a net valence framework which assumes that consumers perceive products or services as having both positive and negative attributes and consumers accordingly make decisions to maximize the net valence caused by the negative and positive attributes of the decision. Valence theory is also consistent with theories by Lewin [24] and Bilkey [4], which provide the theoretical framework for this study.

Furthermore, we understood net valence framework based on the reasoned action in this study. Drawing from TRA, Fintech adoption intention depends on customers' attitude toward Fintech adoption as influenced by behavioral beliefs. More specially, the benefits and risks of Fintech adoption can be considered as behavioral (positive and negative) beliefs that determine attitudes and subsequent behavioral intentions and actions [18]. Accordingly, positive beliefs on Fintech adoption increase perceived benefits, whereas negative beliefs 
result in perceived risks. Based on this notion, this study illustrated that customers determine specific benefits and risks that may arise from Fintech adoption, thereafter combining them into an overall perceived benefits and risks. The result is an overall attitudinal appraisal of Fintech adoption, which leads to the intention to adopt Fintech.

\section{Research model and hypotheses}

This study proposed a benefit and risk framework which integrates the positive and negative factors related to Fintech adoption decision. On the basis of previous studies, perceived benefit and risk were understood as multi-dimensional constructs in this study. The three major dimensions of perceived benefit developed in this study are as follows: economic benefit, convenience, and transaction process. Moreover, the four major factors employed to measure perceived risk are financial, legal, security, and operational risks.

Furthermore, two Fintech groups (i.e., early adopters and late adopters) were utilized to understand the different effects of perceived benefit and risk on Fintech adoption intention. Consequently, we assumed that perceived benefit and risk significantly influence Fintech adoption intention. This study also assumed that different Fintech user types induce varying expected benefits and risks. The overall research model is summarized in Figure. 1.

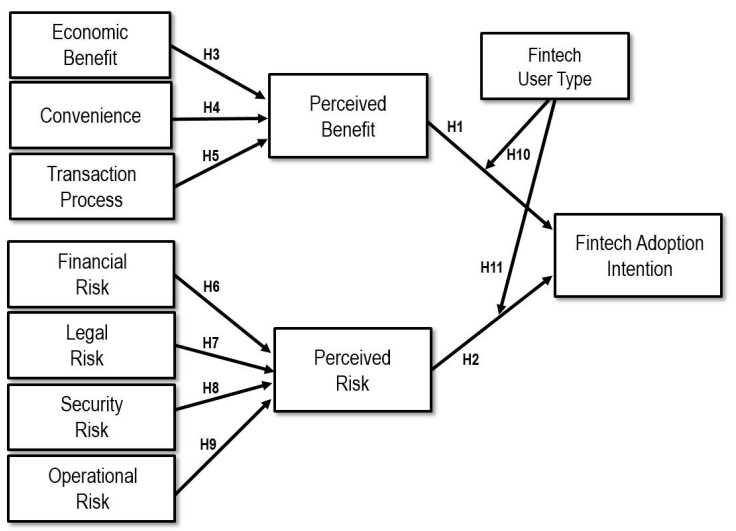

Figure 1. Research model

Customers compare available services and choose the one with the best value [21]. In other words, consumers make a risky decision not to take risks itself, but to obtain gains or benefits. Perceived benefits have been widely utilized as a direct determinant of a particular IS adoption [21, 23]. Perceived benefit is defined as " $a$ customers" perception of the potential that Fintech adoption will result in a positive outcome" in this study. In addition, perceived risk is an important barrier for customers who are considering whether to push through the Fintech adoption. Thus, this study defines perceived risk as " $a$ customers' perception of the uncertainty and the possible negative consequences regarding the Fintech adoption." Therefore, Fintech adoption intention is positively influenced by perceived benefits and negatively influenced by perceived risks. The following hypotheses are proposed:

H1: Perceived benefit is positively related to their Fintech adoption intention.

H2: Perceived risk is negatively related to their Fintech service intention.

The perceived benefits of Fintech are classified into three different aspects: 1) economic benefit; 2) convenience, and 3) transaction process. Economic benefit is the most common and consistent motive that researchers have identified for Fintech [22]. Fintech suggests a lower transaction and capital costs compared with traditional financial service, thereby benefiting customers [26]. Moreover, convenience is pointed out as one of the obvious benefits of Fintech, driven from portability and immediate accessibility $[22,32]$. Convenience refers to flexibility in time and location [29]. Given that mobile device is one of the important channels in Fintech, the convenience through mobile devices determines the levels of perceived benefits on Fintech adoption. Transaction process refers to the transaction related benefits of using Fintech for their financial transactions (e.g., buying, money transferring, lending, and investing). A seamless transaction, which is an important characteristic of Fintech, offers benefits which cuts the middleman by allowing customers to conduct and manage their financial transactions on the cost effective platforms $[8,38]$. Compared with traditional financial transactions, Fintech customers can increase their transaction speed and financial transaction efficiency through seamless transaction. Given the three potential benefits from Fintech adoption, we suggest that the economic benefit, convenience, and transaction process will affect the overall perceived benefit related to positive Fintech adoption. Hence, we hypothesize the following:

H3: Economic benefit is positively related to its perceived benefit.

H4: Convenience is positively related to its perceived benefit. H5: Transaction process is positively related to its perceived benefit.

This study investigated four types of risks as perceived risks of Fintech: 1) financial, 2) legal, 3) security, and 4) operational risks. Financial risk is 
the potential for financial loss in almost all financial transitions of Fintech [12]. Specifically, perceived financial risk is the most consistent predictor of online and mobile user behaviors [28]. Legal risk refers to an unclear legal status and lack of universal regulations of Fintech. Numerous financial and other related regulations block the entry and hinder the growth of the Fintech market in Korea. Especially, the regulations of nonfinancial companies conducting financial business critically interrupt Fintech adoption, which restricts the Korean Fintech market. Security risk is defined as the potential loss due to fraud or a hacker compromising the security of financial transactions in Fintech. Both fraud and hacker intrusion not only causes monetary loss among users, they also violate the privacy of users, which is a major concern of many online and mobile users [23]. Operational risk refers to all potential losses from inadequate or failed internal processes, employees, and systems in Fintech companies [2]. If Fintech companies have problems in their financial systems and operations, then customers will not adopt Fintech. The lack of operational skills and immediate responses for the system problems and the transaction problems result in the distrust and dissatisfaction of customers, hindering Fintech adoption. Therefore, four types of risks might significantly affect perceived risk, which negatively influences Fintech adoption. Thus, we propose the following:

H6: Financial risk is positively related to its perceived risk.

H7: Legal risk is positively related to its perceived risk.

H8: Security risk is positively related to its perceived risk.

H9: Operational risk is positively related to its perceived risk.

The diffusion speed of new technology depends not only on the characteristics of IT itself, but also on the characteristics of users. Karahanna et al. [19] argued that the model used to test the impact of different users (e.g., early adopters versus late adopters) on IS usage can result in new insights. Customers tend to adopt new services or technologies at different periods and rates, and they are classified into different adopter categories on the basis of when customers first begin to adopt (i.e., period of adoption) and the degree to which customers are in adopting and utilizing the innovation (i.e., degree of adoption) [31]. In this study, we classified Fintech users into two types, namely, early and late adopters, based on the timing and behavioral characteristics of a new technical service adoption. Consistent with previous empirical studies $[10,16,20]$, early adopters refer to individuals who gather information to learn more about the benefits of adopting new technology, whereas late adopters refer to people who are more reserved in adopting new services and tend to be skeptical about adoption. Early adopters often function as opinion leaders who can encourage others to adopt innovation by providing evaluative information [31]. Early adopters make important decisions on innovations even though their benefits and losses are still not clearly defined [15]. However, late adopters are not only resistant to change, but also suspicious of agents of change [10]. Late adopters want to be certain that the innovation and benefit of novel products would not fail before adopting them [31]. Escobar-Rodríguez and Romero-Alonso [10] indicated that early adopters willing to use new information technologies and have a positive attitude toward IT innovation than late adopter. However, late adopters is resistant to change as well as have a negative attitude to adopt new services with technology. For the reasons, we infer that the expected benefit and risk on Fintech adoption intention have different, depending on the Fintech user types. Therefore, we build the following hypotheses:

H10: The effect of perceived benefit on Fintech adoption intention in the early adopters is greater than that in the late adopters.

H11: The effect of perceived risk on Fintech adoption intention in the early adopters is greater than that in the late adopters.

\section{Research methodology}

\subsection{Measurement}

To obtain content validity, we developed measurement items based on an intensive literature review. First, we developed comprehensive multipleitem measures based on previous innovation and IS literature for measuring the three perceived benefits (i.e., economic benefit, convenience, and transaction process) and the four perceived risks (i.e., financial, legal, security, and operational risks). Second, Fintech adoption intention was adapted from the measurements defined by Cheng et al. [6] and Lee [23], containing four items for adoption intention. Finally, we employed two dichotomous variables such as the period of adoption and the degree of adoption and then developed two types of Fintech user, namely, early and late adopters based on the two dimensions.

Before conducting the main survey, we performed a pre-test to examine the reliability and validity of the instruments. The pre-test involved 30 respondents with experience using Fintech within the last month. The pre-test results led to the significant refinement and restructuring of the questionnaire and established 
the initial face and internal validity of the measures. All measures are based a seven-point Likert-type scale, ranging from "extremely low" (1) to "extremely high" (7). The structure of measurements used in this study is presented in the Appendix (available upon request from the authors).

\subsection{Sample and Data Collection}

Data collection was outsourced to Embrain Co. (www.embrain.com), a large market research company in Korea with more than 1.8 million panels in various Asian countries. For our main survey, the company sent e-mail invitations to targeted panels. If they accepted the offer to participate, they were guided to the websites we built. The invitation continued until 1,000 panels accepted the offer. Embrain has a solid reputation for managing panels for data authenticity. The company carefully selects participants from a pool of panels based on the specific requests of its clients. The company also maintains a record of respondents to control panel integrity. If inconsistency is detected during a response in the panel, data from that panel are discarded and the respondent is excluded from the panel pool (i.e., company policy on spurious panels). Respondents who used Fintech services within the last month were asked to respond to the entire questionnaire. To ensure that respondents fully understand the survey context, we asked an initial screening question if they are currently using Fintech services. The four types of Fintech obtained are mobile payment, mobile remittance, $\mathrm{P} 2 \mathrm{P}$ lending, and crowdfunding. If a respondent responded negatively to the question, they are no longer allowed to participate in the survey. Table 1 shows the sample characteristics.

Table 1. Profile of the sample

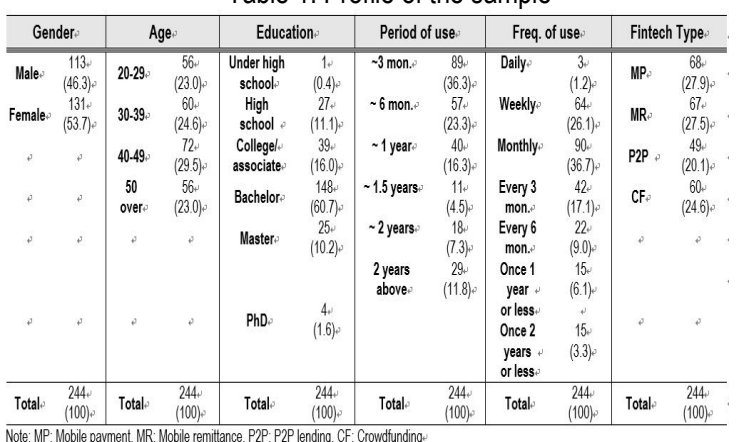

\section{Analysis and results}

In this study, the PLS method was chosen to examine the proposed model and its hypotheses because of the following reasons. First, PLS is generally recommended for the predictive research model where the emphasis is on theory development [11]. Given that this study is an initial attempt to advance a theoretical model that investigates the benefit and risk factors influencing Fintech service behavioral intention, the fit of PLS to exploratory science was highly favorable [7]. Moreover, the ability of PLS to readily handle formative (without MIMIC modeling) and reflective constructs makes it suitable for validating the proposed model [9]. In this model, two independent variables (i.e., perceived benefit and risk) are second order formative constructs, and thus, they are effective for validating the research model using PLS.

As recommended by Gefen et al. [14], a two-stage analytical process was employed for data analysis. The measurement model was first assessed to determine how observed items load on the constructs in the model. The assessment of the structural model then allows for hypothesis testing by examining the relationships among the constructs. Smart PLS version 3.00 was used for analyzing measurement and structural models.

\subsection{Measurement model}

For the measurement model, two constructs (i.e., perceived benefit and risk consisting of three and four first order factors, respectively) were modelled to be formative and (i.e., adoption intention) and reflective, respectively. Based on the rules suggested by Jarvis et al. [17] to determine whether measures of a construct are reflective or formative, two perceived constructs are best modelled as formative at the second order level. The results of the measurement model analysis are shown in Table 2.

Table 2. Results of the measurement model analysis (a) Assessment of reliability and validity

\begin{tabular}{l|c|c|c}
\hline \multicolumn{1}{c|}{ Construct } & Cronbach's Alpha & CR & AVE \\
\hline \hline Economic benefit & 0.867 & 0.919 & 0.792 \\
\hline Convenience & 0.906 & 0.941 & 0.841 \\
\hline Transaction process & 0.810 & 0.889 & 0.728 \\
\hline Financial risk & 0.796 & 0.881 & 0.712 \\
\hline Legal risk & 0.877 & 0.916 & 0.731 \\
\hline Security risk & 0.910 & 0.943 & 0.848 \\
\hline Operational risk & 0.860 & 0.915 & 0.781 \\
\hline Adoption intention & 0.901 & 0.931 & 0.770 \\
\hline
\end{tabular}


(b) Correlations and square root of AVE

\begin{tabular}{|c|c|c|c|c|c|c|c|c|c|}
\hline $\begin{array}{l}\text { Construct } \\
\end{array}$ & $\begin{array}{l}\text { Means } \\
\text { (S.D.) }\end{array}$ & 1 & 2 & 3 & 4 & 5 & 6 & 7 & 8 \\
\hline 1. Economic benefit & $\begin{array}{l}4.844 \\
(0.980)\end{array}$ & 0.890 & & & & & & & \\
\hline 2. Convenience & $\begin{array}{l}5.270 \\
(0.969)\end{array}$ & $0.574^{*}$ & 0.917 & & & & & & \\
\hline $\begin{array}{l}\text { 3. Transaction } \\
\text { process }\end{array}$ & $\begin{array}{l}4.772 \\
(0.954)\end{array}$ & $0.520^{* *}$ & $0.591^{* *}$ & 0.853 & & & & & \\
\hline 4. Financial risk & $\begin{array}{l}4.205 \\
(0.932)\end{array}$ & $-0.167^{* *}$ & $-0.172^{* *}$ & $-0.160^{*}$ & 0.844 & & & & \\
\hline 5. Legal risk & $\begin{array}{l}3.974 \\
(0.910) \\
\end{array}$ & -0.096 & $-0.237^{* t}$ & $-0.128^{* \prime}$ & $0.497^{* *}$ & 0.855 & & & \\
\hline 6. Security risk & $\begin{array}{l}4.615 \\
(1.090)\end{array}$ & -0.090 & 0.026 & -0.005 & $0.472^{*+}$ & $0.273^{* *}$ & 0.912 & & \\
\hline 7. Operational risk & $\begin{array}{l}4.332 \\
(0.927) \\
\end{array}$ & -0.064 & -0.114 & $-0.103^{*}$ & $0.373^{*}$ & $0.406^{* *}$ & $0.587^{* *}$ & 0.884 & \\
\hline 8. Adoption intention & $\begin{array}{l}4.718 \\
(0.867)\end{array}$ & $0.381^{* \prime}$ & $0.562^{* *}$ & $0.503^{* *}$ & $-0.213^{* *}$ & $-0.228^{*}$ & $-0.235^{\prime \prime}$ & $-0.300^{* \prime}$ & 0.987 \\
\hline
\end{tabular}

\subsection{Structural model}

With an adequate measurement model and a suitably low level of multicollinearity, the proposed hypotheses are tested with PLS. The path coefficients, $t$-values, and $R$-squares for testing the structural model are shown in Figure 2. Tests of significance of all paths in the research model were performed using the PLS bootstrap resampling procedure. As shown in Figure 2, all paths within the model were supported at the 0.01 level. Furthermore, it is critical to note that the proposed model accounted for $39.1 \%$ variance in Fintech service adoption intention.

Figure 2 shows that perceived benefit had a significant positive effect on Fintech service adoption intention $(\beta=0.543 ; p<0.01)$. Thus, $\boldsymbol{H} 1$ was supported. Perceived risk was negatively related to Fintech the adoption intention $(\beta=0 .-233 ; p<0.01)$, providing support for H2. Thus, perceived benefit positively affects, whereas perceived risk negatively influences the respondents' willingness to adopt Fintech service. Our results also show that the effect of perceived benefit was greater than that of perceived risk, indicating that overall, respondents are willing to adopt Fintech in Korea.

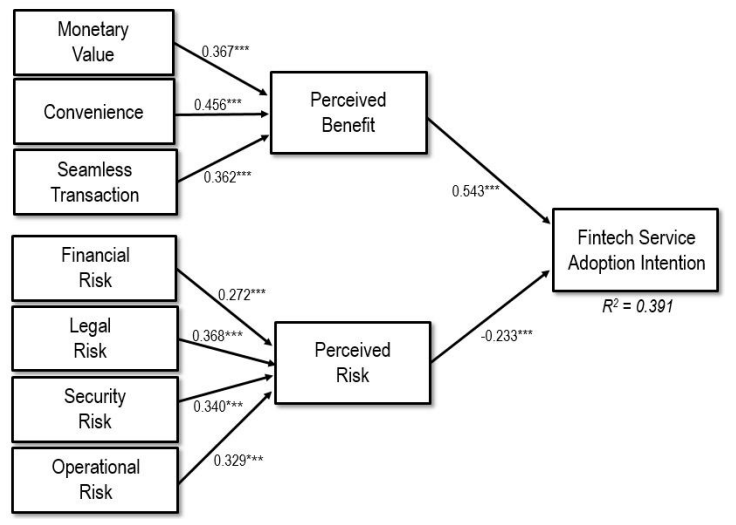

Figure 2. Results of hypotheses tests for the total group
Figure 2 also presents that the economic benefits, convenience, and seamless transaction had significant positive effects on perceived benefit $(\beta=0.367$; $p<0.01 ; \quad \beta=0.456 ; \quad p<0.01 ; \quad \beta=0.362 ; \quad p<0.01)$, supporting $\mathrm{H} 3, \mathrm{H} 4$, and $\mathrm{H} 5$, respectively. The path coefficient between convenience and perceived benefit was greater than the causal relationship between economic benefit/seamless transaction and perceived benefit. The path coefficient between economic and perceived benefits was as important as that between seamless transaction and perceived benefit. The results also show that financial, legal, security, and operational risks had positive significant effects on perceived risk $(\beta=0.272 ; p<0.01 ; \beta=0.368$; $p<0.01 ; \quad \beta=0.340 ; \quad p<0.01 ; \quad \beta=0.329 ; \quad p<0.01)$, providing support for $\mathrm{H6}, \mathrm{H} 7, \mathrm{H} 8$, and $\mathrm{H} 9$, respectively. The highest loading of legal risk indicated a strong impact on perceived risk, whereas financial risk had the lowest impact. The effect of security risk was greater than that of operational risk on perceived risk.

In this study, Fintech users were basically classified into the three groups such as early adopters, adopters, and late adopters depending on the period of adoption and the degree of adoption, as shown in Table 3. To effectively distinguish the differences between user groups, this study employed the two user types, namely, the early $(\mathrm{N}=55)$ and late adopters $(\mathrm{N}=82)$.

Table 3. Sample classification

\begin{tabular}{|c|c|c|c|c|}
\hline & & \multicolumn{2}{|c|}{ Degree of adoption } & \multirow{2}{*}{ Total } \\
\hline & & Low: & High- & \\
\hline \multirow{2}{*}{$\begin{array}{l}\text { Period of } \\
\text { adoption }\end{array}$} & Low & Late adopters $(\mathrm{N}=82)$ & Adopters $(\mathrm{N}=43)$ & 125 \\
\hline & High & Adopters $(\mathrm{N}=64)$; & Early adopters $(\mathrm{N}=55)$ & 119, \\
\hline \multicolumn{2}{|c|}{ Total } & 146 & 98 & 224 \\
\hline
\end{tabular}

Each group underwent measurement model tests, such as exploratory factor analysis and multicollinearity. We then tested the H10 and H11 hypotheses on each group. Figures 3 and 4 show the results of the moderation test of Fintech user type. As shown in Figures 3 and 4, the perceived benefit and risk in both early and late adopter groups were positively significant on Fintech adoption intention. The effect of perceived benefit $(\beta=0.657 ; p<0.01)$ in early adopters was greater than that $(\beta=0.255 ; p<$ 0.01) of late adopters, thereby supporting H10. However, the late adopter group indicated a stronger coefficient path $(\beta=-0.281 ; p<0.01)$ of perceived risk than the early adopter group $(\beta=-0.251 ; p<0.01)$, supporting H11. The results show that the $R^{2}$ by Fintech adoption intention in both early and late adopters were $61.5 \%$ and $14.4 \%$, respectively. 


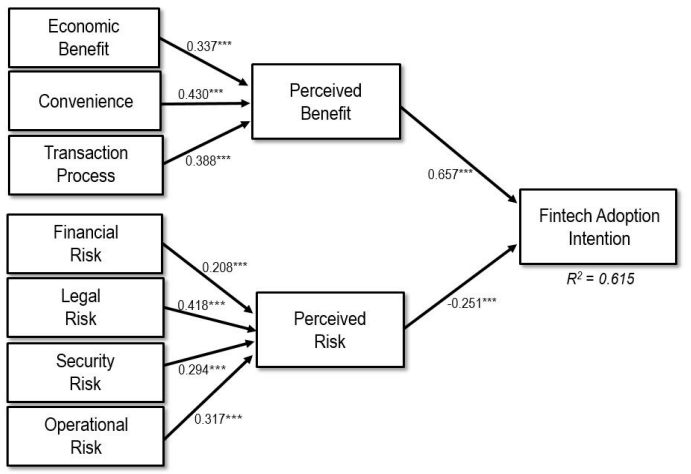

Figure 3. Results of hypotheses tests for the early adopters

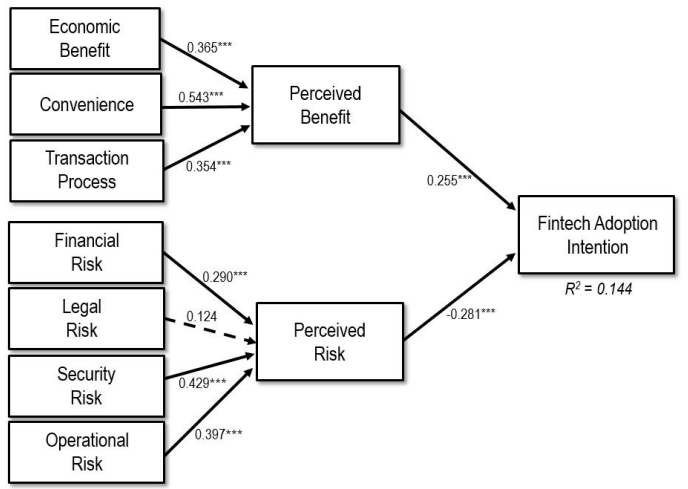

Figure 4. Results of hypotheses tests for the late adopters

\section{Discussion and conclusion}

This goal of this study was to clarify why customers are willing or hesitant to adopt an emergent financial service and to identify different benefit and risk perceptions depending on the user types. Fintech service. The findings of this study effectively show the key determinants and barriers of Fintech adoption intention.

Our study theoretically emphasizes several points. First, this study shed light on important issues related to customer intentions toward Fintech that have not been addressed by previous studies. Although Fintech has been receiving growing attention, few empirical studies on perception of Fintech adoption has been conducted. A more detailed understanding of Fintech adoption in the IS field must be achieved before more significant progress can be made. Therefore, this study employed the positive and negative factors which influence Fintech adoption based on IS literature. This study shows their relationship with each other or how they work in combination to influence adoption intention and decision. The theoretical and empirical demonstration of the effects of perceived benefit and risk on Fintech adoption is an important research contribution of this study.

Second, this study demonstrates the decisionmaking process of customers which helps provide insights for researchers. Our findings reveal the benefits and risks that contribute to the formation of adoption intentions and the extent to which they do so. This study advances the understanding of the process of balancing different salient beliefs regarding benefit and risk factors prior to decision. Consequently, the decision-making process becomes more transparent and traceable.

Third, this study shows that the effects of perceived benefit and risk on Fintech adoption intention are different depending on the Fintech user type. The speed of diffusion of an emerging service with new technologies depends not only on the characteristics of the service itself, but also on the characteristics of the user who adopt it [36]. Thus, Fintech companies should consider their user types before the positive and negative factors realize the expected integrative effects on Fintech adoption intention. User-specific factors are major contributors to the success of Fintech business.

The results of this study also have several practical implications. First, this study highlights that perceived benefit is a more influential factor than perceived risk on Fintech adoption. The findings imply that customers are mainly willing to adopt Fintech, but some factors hinder their adoption. Thus, controlling the risks of Fintech is also as important as enhancing the benefits. Given that building a riskfree transaction environment is more difficult than providing benefits to customer, Fintech companies should search for risk-reducing strategies that might assist in inspiring high confidence in potential customers. Second, this study provides Fintech managers insights into the factors they should emphasize or avoid when offering Fintech services to customers. The empirical results show that the three perceived benefit and four perceived risk facets have significant effects on the behavioral intention to adopt Fintech. Legal risk has the biggest negative effect $(\beta=0.452 ; p<0.01)$, whereas convenience has the strongest positive effect $(\beta=0.363 ; p<0.01)$ in the total group. This finding is particularly important for managers as they decide how to allocate resources to retain and expand their current customer base. Hence, this study provides valuable practical guidance to manager for enhancing Fintech adoption.

Third, managers should clearly understand the differences between benefit and risk according to user types. Such a distinction enables Fintech companies to deeply understand the characteristics of each Fintech user and effectively deliver service while meeting customer expectations and demands, 
thereby improving the adoption of service. The managers of Fintech companies should pay attention to these factors in order to increase adoption intention

Despite the aforementioned contributions, this study has a few limitations. First, this study focused on a specific set of perceived benefit and risk reflecting those used in prior research. Future studies may include other benefits and risks associated with Fintech service adoption that may grow in important over time. Second, given the innovative nature of Fintech and the infancy stage of Fintech service implementation, this study merely focused on behavioral intention as the dependent variable to interpret the theory-driven actual behavioral in the early adoption stage. Thus, measurement reliability should be further improved in future research to employ additional methods, such as a field study and/or longitudinal analysis, for a closer observance and investigation on the differences between adopters and non-adopters in the later stages of Fintech service implementation.

Third, measurements of all constructs in this study were collected at the same point in time and via the same self-reported instrument. According to [Straub et al. [35]], the potential for common methods variance may exist. Therefore, future research using a rich research methodology, combining quantitative and qualitative methods is called for. This multimethodological triangulation method is necessary for researchers to extract potential variables that will help explain the improved variances of the dependent variable. Fourth, focusing on multi-dimensional benefit and risk factors, this research intended to provide a comprehensive yet parsimonious decisionmaking model for Fintech service adoption, whereas the current model explains $39.1 \%$ of the variance in behavioral intention. In future research, we hope to further improve the explanatory power by including additional constructs.

Fifth, the study was limited to four types of Fintech service: mobile payment, mobile remittance, P2P lending, and crowdfunding. Therefore, our findings cannot be generalized to other Fintech services (e.g., bitcoin, ethereum, internet banking, personal financing, equity financing, retain investment, and Fintech tool and software). Future research can extend and include the investigation to other Fintech services. Finally, our findings may not be completely generalizable because our sample was restricted to Korea which, in terms of national characteristics, is different from other Fintech technology advancing nations such as United States, United Kingdom, China, and Singapore. Therefore, the results of this study must be carefully interpreted. We hope that future research will consider various national characteristics to explain the issue of Fintech service adoption across different nations at individual level.

\section{Acknowledgement}

This work was supported by the MISP (Ministry of Science, ICT \& Future Planning), Korea, under the National Program for Excellence in Software (R2215-16-1005) supervised by the IITP (Institute for Information \& communications Technology Promotion)

\section{References}

[1] Arner, D.W., J.N. Barberis, and R.P. Buckley, The Evolution of Fintech: A New Post-Crisis Paradigm?, in, University of Hong Kong Hong Kong, 2015.

[2] Barakat, A., and K. Hussainey, "Bank governance, regulation, supervision, and risk reporting: Evidence from operational risk disclosures in European banks", International Review of Financial Analysis. 30(2), 2013, pp. 254-273.

[3] Barberis, J., "The rise of finTech: Getting Hong Kong to lead the digital financial transition in APAC", Fintech Report. Fintech HK.13(4), 2014, pp.

[4] Bilkey, W.J., "A psychological approach to consumer behavior analysis", Journal of Marketing. 18(1), 1953, pp. 18-25.

[5] Chan, R., Asian Regulator Seek FinTech Balance, in: Finance Asia, Finance Asia, Hong Kong, 2015.

[6] Cheng, T.E., D.Y. Lam, and A.C. Yeung, "Adoption of internet banking: an empirical study in Hong Kong", Decision support systems. 42(3), 2006, pp. $1558-1572$.

[7] Chin, W.W., "Commentary: Issues and opinion on structural equation modeling", MIS Quarterly. 22(1), 1998, pp. vii-xvi.

[8] Chishti, S., How Peer to Peer Lending and Crowdfunding Drive the FinTech Revolution in the UK, in: Banking Beyond Banks and Money, Springer, 2016, pp. 55-68.

[9] Diamantopoulos, A., P. Riefler, and K.P. Roth, "Advancing formative measurement models", Journal of Business Research. 61(12), 2008, pp. 1203-1218.

[10] Escobar-Rodríguez, T., and M. Romero-Alonso, "The acceptance of information technology innovations in hospitals: differences between early and late adopters", Behaviour \& Information Technology. 33(11), 2014, pp. 1231-1243.

[11] Fornell, C., and F.L. Bookstein, "Two structural equation models: LISREL and PLS applied to 
consumer exit-voice theory", Journal of Marketing Research. 24(2), 1982, pp. 440-452.

[12] Forsythe, S., C. Liu, D. Shannon, and L.C. Gardner, "Development of a scale to measure the perceived benefits and risks of online shopping", Journal of Interactive Marketing. 20(2), 2006, pp. 55-75.

[13] Freedman, R.S., Introduction to financial technology, Academic Press, 2006.

[14] Gefen, D., D. Straub, and M.-C. Boudreau, "Structural equation modeling and regression: Guidelines for research practice", Communications of the Association for Information Systems. 4(1), 2000, pp. 7.

[15] Harrison, T., and K. Waite, "A time-based assessment of the influences, uses and benefits of intermediary website adoption", Information \& Management. 43(8), 2006, pp. 1002-1013.

[16] Hong, W., and K. Zhu, "Migrating to internetbased e-commerce: Factors affecting e-commerce adoption and migration at the firm level", Information \& Management. 43(2), 2006, pp. 204221.

[17] Jarvis, C.B., S.B. MacKenzie, and P.M. Podsakoff, "A critical review of construct indicators and measurement model misspecification in marketing and consumer research", Journal of Consumer Research. 30(2), 2003, pp. 199-218.

[18] Jurison, J., "The role of risk and return in information technology outsourcing decisions", Journal of Information Technology. 10(4), 1995, pp. 239.

[19] Karahanna, E., D.W. Straub, and N.L. Chervany, "Information technology adoption across time: a cross-sectional comparison of pre-adoption and postadoption beliefs", MIS Quarterly. 19(2), 1999, pp. 183-213.

[20] Kim, C., M. Mirusmonov, and I. Lee, "An empirical examination of factors influencing the intention to use mobile payment", Computers in Human Behavior. 26(3), 2010, pp. 310-322.

[21] Kim, D.J., D.L. Ferrin, and H.R. Rao, "A trustbased consumer decision-making model in electronic commerce: The role of trust, perceived risk, and their antecedents", Decision support systems. 44(2), 2008, pp. 544-564.

[22] Kuo Chuen, D.L., and E.G. Teo, "Emergence of FinTech and the LASIC principles", Journal of Financial Perspectives. 3(3), 2015, pp. 24-36.

[23] Lee, M.-C., "Factors influencing the adoption of internet banking: An integration of TAM and TPB with perceived risk and perceived benefit", Electronic Commerce Research and Applications. 8(3), 2009, pp. 130-141.
[24] Lewin, K., "Forces behind food habits and methods of change", Bulletin of the national Research Council. 108(1043), 1943, pp. 35-65.

[25] Luo, X., H. Li, J. Zhang, and J.P. Shim, "Examining multi-dimensional trust and multifaceted risk in initial acceptance of emerging technologies: An empirical study of mobile banking services", Decision support systems. 49(2), 2010, pp. 222-234.

[26] Mackenzie, A., "The fintech revolution", London Business School Review. 26(3), 2015, pp. 50-53.

[27] Mallat, N., "Exploring consumer adoption of mobile payments-A qualitative study", The Journal of Strategic Information Systems. 16(4), 2007, pp. 413-432.

[28] Melewar, T., S. Alwi, M. Tingchi Liu, J.L. Brock, G. Cheng Shi, R. Chu, and T.-H. Tseng, "Perceived benefits, perceived risk, and trust: Influences on consumers' group buying behaviour", Asia Pacific Journal of Marketing and Logistics. 25(2), 2013, pp. 225-248.

[29] Okazaki, S., and F. Mendez, "Exploring convenience in mobile commerce: Moderating effects of gender", Computers in Human Behavior. 29(3), 2013, pp. 1234-1242.

[30] Peter, J.P., and L.X. Tarpey, "A comparative analysis of three consumer decision strategies", Journal of Consumer Research. 2(1), 1975, pp. 29-37. [31] Rogers, E.M., Diffusion of Innovations, 4th ed. ed., The Free Press, New York, 1995.

[32] Sharma, S., and J.A. Gutiérrez, "An evaluation framework for viable business models for $\mathrm{m}$ commerce in the information technology sector", Electronic Markets. 20(1), 2010, pp. 33-52.

[33] Skan, J., J. Dickerson, and S. Masood, The Future of Fintech and Banking, 2014.

[34] Srivastava, S.C., S. Chandra, and Y.-L. Theng, "Evaluating the role of trust in consumer adoption of mobile payment systems: An empirical analysis", Communications of the Association for Information Systems. 27(3), 2010, pp. 561-588.

[35] Straub, D., M. Limayem, and E. KarahannaEvaristo, "Measuring system usage: Implications for IS theory testing", Management Science. 41(8), 1995, pp. 1328-1342.

[36] Teo, T., C.B. Lee, and C.S. Chai, "Understanding pre-service teachers' computer attitudes: applying and extending the technology acceptance model", Journal of computer assisted learning. 24(2), 2008, pp. 128-143.

[37] Wilkie, W.L., and E.A. Pessemier, "Issues in marketing's use of multi-attribute attitude models", Journal of Marketing Research.17(3), 1973, pp. 428441. 
[38] Zavolokina, L., M. Dolata, and G. Schwabe, "FinTech-What's in a Name?" in proceedings of International Conference of Information Systems, 2016.

\section{Appendix A:}

Structure of the survey instrument

\section{Constructs/ Questionnaire}

Economic benefit (EB)

EB1. Using Fintech is cheaper than using traditional financial services.

EB2. I can save money when I use Fintech.

EB3. I can use various financial services with low cost when I use Fintech.

\section{Convenience (CV)}

CV1. I can use financial services very fast when I use Fintech.

CV 2. I can use financial services anytime anywhere when I use Fintech.

CV 3. I can use financial services easily when I use

Fintech.

\section{Transaction process (TP)}

TP1. I can control my money without middle man when I use Fintech.

TP2. I can use various financial services at the same time (e.g., one stop processing) when I use Fintech.

TP3. I can have the peer-to-peer transactions between providers and users without middle man when I use Fintech.

\section{Financial risk (FR)}

FR1. Financial losses are likely when I use Fintech.

FR2. Financial fraud or payment frauds are likely when I use Fintech.

FR3. Financial losses due to lack of the interoperability with other services are likely when I use Fintech.

\section{Legal risk (LR)}

LR1. Using Fintech is uncertain due to many regulations.

LR2. It is not easy to use a Fintech due to the government regulation.

LR3. There is a legal uncertainty for Fintech users. LR4. It is difficult to use various Fintech like other countries due to the government regulation.

\section{Security risk (SR)}

SR1. I worry about the abuse of my financial information (e.g., transaction and private information) when I use Fintech.

SR2. My financial information is not secure when I use Fintech.

SR3. I worry that someone can afford to access my financial information when I use Fintech.

\section{Operational risk (OR)}

OR1. Fintech companies are not willing to solve the issues when financial losses or financial information leakage happen.

OR2. The organizational responses of Fintech companies are too slow when financial losses or financial information leakage happen.

OR3. I worry about the way of Fintech companies respond to financial loss or financial information leakage.

Adoption intention (AI)

AI1. I would positively consider Fintech in my choice set.

AI2. I would prefer Fintech.

AI3. I would intend to continue to use Fintech.

AI4. I will use Fintech in the future. 